\title{
Bibliometric Analysis of the Journal of Orthopaedic Research from 1991 To 2018
}

\author{
Yuh-Shan Ho* \\ Trend Research Centre, Taiwan
}

ISSN: 2576-8875

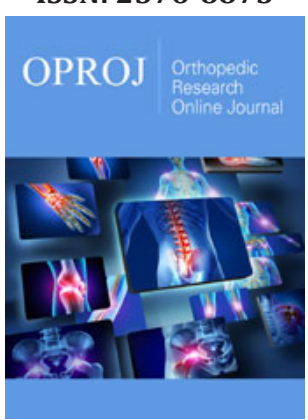

${ }^{* 1}$ Corresponding author: Yuh-Shan Ho, Trend Research Centre, Asia University, Taichung 41354, Taiwan

Submission: 淟 November 25, 2018

Published: 毕December 06, 2019

Volume 6 - Issue 2

How to cite this article: Yuh-Shan Ho. Bibliometric Analysis of the Journal of Orthopaedic Research from 1991 To 2018. Ortho Res Online J. 6(2). OPROJ.000632.2019. DOI: $10.31031 /$ OPROJ.2019.06.000632

Copyright@: Yuh-Shan Ho, This article is distributed under the terms of the Creative Commons Attribution 4.0 International License, which permits unrestricted use and redistribution provided that the original author and source are credited.

\begin{abstract}
A chronological survey of papers was conducted to investigate the journal titled Journal of Orthopaedic Research in Science Citation Index Expanded (SCI-EXPANDED) between 1991 and 2018. Performances of countries, institutes, and authors, including total, single, collaborative, first author, and corresponding author publications were analyzed. Citation indicators including the total number of citations since publication to the end of 2018, the number of citations in 2018, total number of citations in the publication year, total number of citations per number of years, and citations per publication were applied to evaluate highly cited articles. Comparison of the articles contributing most to impact factor and highly cited articles were discussed. In addition, journal impact factor contributors and journal impact factor contributing articles were presented.
\end{abstract}

Keywords: Bibliometric; SCI-EXPANDED; Citations per publication; Journal impact factor contributing articles; JIF contributors

\section{Introduction}

The bibliometric analysis of publications can provide insight to improve the understanding by editors and readers of an academic journal's direction [1]. The Journal of Orthopaedic Research with ISO Abbreviation title J Orthop Res has been indexed in the Science Citation Index Expanded (SCI-EXPANDED) and classified in Web of Science category of orthopedics since 1985. In this category, bibliometric analyses of journals have been reported to investigate journals' development and impact in research fields, including journals Physical Therapy [2,3], Journal of Orthopaedic \& Sports Physical Therapy [4], Acta Orthopaedica et Traumatologica Turcica [5], International Orthopaedics [6], Knee [7], Journal of Orthopaedic Trauma [8], and Spine [9]. Recently authorship trends in the Journal of Orthopaedic Research [10] and a bibliometric analysis of classic publications in Web of Science category of orthopedics [11] were also reported. Document types, languages, publication trends, and publications of country, institution, and author were generally revealed to provide basic information about a journal [1,12]. In addition, journals' impact factor, which was created in the early 1960s [13], has become a staple in many types of analyses of a journal's scientific impact [14]. Publication indicators such as total, independent, collaborative, first author, and corresponding author publications [15] as well as citation indicators including the total number citations from Web of Science Core Collection since publication to the end of the most recent year $[16,17]$ and the number of citations in the most recent year [18] were generally applied to evaluate journals $[1,19]$.

In this study, the bibliometric method was employed to obtain an overview of Journal of Orthopaedic Research from 1991 to 2018. General analysis including publication characteristics and trends were presented. Furthermore, relationship among journal's impact factor, its contributors, and highly cited publications were discussed.

\section{Methodology}

Documents used in this study were derived from the Science Citation Index Expanded (SCI-EXPANDED) of the Web of Science core Collection, Clarivate Analytics (formerly known as the Thomson Reuters and the Institute for Scientific Information). The keyword phrase "Journal of Orthopaedic Research" was searched as publication name based on SCI-EXPANDED (updated on 20 November 2019). All document information from SCI-EXPANDED was checked and downloaded into Microsoft Excel 2016 [20,21]. Collaboration type of country 
and institution was determined by the affiliation of the authors. In the SCI-EXPANDED, the corresponding author is designated as the "reprint" author; this study uses as the term "corresponding author" [18]. In a single author article where authorship is unspecified, the single author is both first author and corresponding author [22]. Similarly, in a singly institutional article, the institution is classified as the first author institution and the corresponding author institution [22]. Only the last corresponding authors were considered in articles having multiple corresponding authors. Affiliations originating from England, Scotland, Northern Ireland, and Wales were reclassified as being from the United Kingdom (UK) [23]. Affiliations in Hong Kong before 1997 were included with China [24].

\section{Results and Discussion}

\section{Characteristics of document type}

The distributions of document types at the Web of Science and their citations per publication $\left(\mathrm{CPP}_{\text {year }}=\mathrm{TC}_{\text {year }} / \mathrm{TP}\right)$ have been analyzed for journals by Ho's group, for example Polish Journal of Environmental Studies [25], Journal of Membrane Science [1], and Revista de Biología Tropical/International Journal of Tropical Biology and Conservation [12]. Journal of Orthopaedic Research published 5,589 documents in 11 Web of Science document types from 1991 to 2018 (Table 1). Article $(5,329)$ was the dominant document type comprising $95 \%$ of 5,589 productions with the third ranking of APP (5.8), followed by letters (1.4\%), proceedings papers (1.3\%), and reviews (1.1\%). Among the 11 document types, proceedings papers had the highest $C P P_{2018}$ of 50 , followed by articles with $C P P_{2018}$ of 33, notes (17), and reviews (16). It should be pointed out that $C P P_{2018}$ of review is much lower than that of articles. Proceedings papers had the highest number of authors per publication $(A P P=8.5)$ followed by corrections (5.9). Only the articles were used for further study.

Table 1: Document types for Journal of Orthopaedic Research (1991-2018).

\begin{tabular}{|c|c|c|c|c|c|c|}
\hline Document type & TP & $\%$ & $\mathrm{AU}$ & APP & $\mathrm{TC}_{2018}$ & $\mathrm{CPP}_{2018}$ \\
\hline Article & 5,329 & 95 & 30,744 & 5.8 & 177,543 & 33 \\
\hline Letter & 81 & 1.4 & 194 & 2.4 & 69 & 0.85 \\
\hline Proceedings paper & 75 & 1.3 & 638 & 8.5 & 3766 & 50 \\
\hline Review & 63 & 1.1 & 293 & 4.7 & 9,96 & 16 \\
\hline Editorial material & 47 & 0.84 & 116 & 2.5 & 104 & 2.2 \\
\hline Correction & 29 & 0.52 & 172 & 5.9 & 18 & 0.62 \\
\hline Note & 24 & 0.43 & 110 & 4.6 & 403 & 17 \\
\hline Addition correction & 7 & 0.13 & 20 & 2.9 & 8 & 1.1 \\
\hline Biographical item & 7 & 0.13 & 10 & 1.4 & 0 & 0 \\
\hline News item & 1 & 0.018 & 1 & 1.0 & 0 & 0 \\
\hline Reprint & 1 & 0.018 & 1 & 1.0 & 1 & 1.0 \\
\hline
\end{tabular}

TP: Number of publications; AU: Number of authors; APP: Number of authors per publication; $\mathrm{TC}_{2018}$ : The total num-

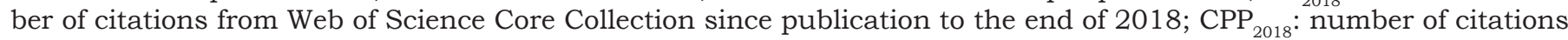
$\left(\mathrm{TC}_{2018}\right)$ per publication (TP).

\section{Characteristics of journal's Impact Factor (IF)}

According to the Journal Citation Reports (JCR) in 2018, JCR indexed 9,258 journals with citation references across 178 Web of Science categories in SCI-EXPANDED. The journal impact factor $(I F)$ is defined as all citations to the journal in the current JCR year to items published in the previous two years, divided by the total number of scholarly items (these comprise articles, reviews, and proceedings papers) published in the journal in the previous two years.

The journal impact factor has a simple formula:

$F_{\text {Year }}=\frac{C_{\text {year }-2}+C_{\text {year }-1}}{\boldsymbol{P}_{\text {Year }-2}+\boldsymbol{P}_{\text {Year }-1}}$

where $I F_{\text {year }}$ is journal impact factor in a specific JCR year, $C_{\text {year-2: }}$ : citations from JCR year to items in "year -2 ", $C_{\text {year- } 1}$ : citations from JCR year to items in "year - 1", $T P_{\text {year-2 }}$ : citable items in "year - 2",
$T P_{\text {year- } 1}$ : citable items in "year - 1 ". The denominator is comprised of three document types such as reviews, articles, and proceedings papers. An item with any other document type is excluded from the denominator.

The top 21 most impact factor contributing articles were listed in Table 2. 29\% and 14\% of them were published in 2007 and 2009 respectively and $10 \%$ were published in 2015, 2011, 2005, and 2003 respectively. Only one top impact factor contributing article was published in 2012, 2008, 2004, and 2002, respectively. $67 \%$ and $52 \%$ of the top 21 most impact factor contributing articles were ranked top 21 in terms of $T C_{\text {year-2 }}$ and $T C_{\text {year-1 }}$ respectively. However, only $14 \%, 14 \%, 24 \%$, and $57 \%$ of the top 21 most impact factor contributing articles were ranked top 21 in terms of $C_{0}$, total number of citations from Web of Science Core Collection in publication year [15]; $T C_{2018}$, total number of citations from web of science core collection since publication to the end of 2018 [16,17]; 
$C_{2018}$, total number of citations from web of science core collection in 2018 [18], and TCPY, total number of citations per number of year, $T C_{2018} /$ year [18] respectively. Furthermore, only $47 \%$ and $34 \%$ of the top 100 impact factor contributing articles were found in the top 100 articles in terms of $C_{2018}$ and $T C_{2018}$, respectively. Article entitled "Post-traumatic osteoarthritis: Improved understanding and opportunities for early intervention" by Anderson et al. [26] from USA was not the top high impact factor contributing article (ranked $1^{\text {st }}$ ) but also the most impact article in the recent year with $C_{2018}$ of 35 (ranked $5^{\text {th }}$ ) in J Orthop Res However the article ranked $40^{\text {th }}$ in $T C_{2018}$ with 243 . It was generally accepted that time is needed to accumulate total number of citations for an article. Similarly, article entitled "Distribution of in situ forces in the anterior cruciate ligament in response to rotatory loads" by Gabriel et al. [27] from University of Pittsburgh in USA was not the top high impact factor contributing article (ranked $6^{\text {th }}$ ) but also the highly cited with $T C_{2018}$ of 383 (ranked 11 $1^{\text {th }}$ ). It can be concluded that the impact factor of journal is used to evaluate a journal's relative importance, especially when compared to others in the same field but not appropriate to be used when compared to individual research performance. It was also reported in web of science that the journal impact factor is a publication-level metric. It does not apply to individual papers or subgroups of papers that appeared in the publication. Additionally, it does not apply to authors of papers, research groups, institutions, or universities.

Table 2: Top 21 journal impact factor contributing articles in Journal of Orthopaedic Research.

\begin{tabular}{|c|c|c|c|c|c|c|c|}
\hline $\begin{array}{c}\text { Rank } \\
\left(\mathrm{TC}_{\text {year-1 }}{ }^{+}\right. \\
\left.\mathrm{TC}_{\text {year-2 }}\right)^{+}\end{array}$ & $\begin{array}{c}\text { Rank } \\
\left(\mathrm{TC}_{\text {year-2}}\right)\end{array}$ & $\begin{array}{c}\text { Rank } \\
\left(\mathrm{TC}_{\text {year-1}}\right)\end{array}$ & $\begin{array}{l}\text { Rank } \\
\left(C_{0}\right)\end{array}$ & $\begin{array}{c}\text { Rank } \\
\left(\mathrm{TC}_{2018}\right)\end{array}$ & $\begin{array}{l}\text { Rank } \\
\left(C_{2018}\right)\end{array}$ & $\begin{array}{c}\text { Rank } \\
\text { (TCPY) }\end{array}$ & Articles \\
\hline $1(66)$ & $2(31)$ & $3(35)$ & $540(1)$ & $40(243)$ & $5(35)$ & $2(30)$ & Anderson et al. [26] \\
\hline $2(62)$ & $1(42)$ & $22(20)$ & $2(8)$ & $62(202)$ & $3(38)$ & $3(29)$ & Fregly et al. (2012) \\
\hline $3(59)$ & $18(19)$ & $1(40)$ & $1532(0)$ & $25(290)$ & $38(17)$ & $13(21)$ & Anitua et al. (2005) \\
\hline $4(54)$ & $15(21)$ & $4(33)$ & $540(1)$ & $24(293)$ & $16(23)$ & $9(24)$ & Zhao et al. (2007) \\
\hline $4(54)$ & $24(17)$ & $2(37)$ & $226(2)$ & $12(363)$ & $28(19)$ & $4(26)$ & Darling and Athanasiou (2005) \\
\hline $6(48)$ & $24(17)$ & $6(31)$ & $104(3)$ & $76(187)$ & $169(10)$ & $32(16)$ & Murray et al. [35] \\
\hline $6(48)$ & $36(16)$ & $5(32)$ & $104(3)$ & $11(383)$ & $84(13)$ & $4(26)$ & Gabriel et al. [27] \\
\hline $8(45)$ & $9(23)$ & $14(22)$ & $104(3)$ & $45(230)$ & $104(12)$ & 17 (19) & Schnabel et al. (2007) \\
\hline $9(44)$ & $51(14)$ & $7(30)$ & $1532(0)$ & $18(329)$ & $675(5)$ & 17 (19) & Noth et al. (2002) \\
\hline $10(43)$ & $5(24)$ & 25 (19) & $1(9)$ & $606(71)$ & $28(19)$ & $23(18)$ & Risbud et al. (2015) \\
\hline $11(42)$ & $64(13)$ & $8(29)$ & $226(2)$ & $26(288)$ & $65(14)$ & $9(24)$ & Luu et al. (2007) \\
\hline $11(42)$ & $12(22)$ & $22(20)$ & $540(1)$ & $31(260)$ & $131(11)$ & $32(16)$ & Dragoo et al. (2003) \\
\hline $13(41)$ & $5(24)$ & 39 (17) & $540(1)$ & $558(75)$ & $6(33)$ & 17 (19) & Thomopoulos et al. (2015) \\
\hline $14(40)$ & $9(23)$ & $39(17)$ & $540(1)$ & $91(177)$ & $20(21)$ & $23(18)$ & Mccarrel and Fortier (2009) \\
\hline $14(40)$ & $12(22)$ & $30(18)$ & $14(6)$ & $43(231)$ & $84(13)$ & $13(21)$ & Butler et al. (2008) \\
\hline $14(40)$ & $3(27)$ & $81(13)$ & $104(3)$ & $50(222)$ & $104(12)$ & $17(19)$ & Christenson et al. (2007) \\
\hline $17(39)$ & $24(17)$ & $14(22)$ & $226(2)$ & $61(203)$ & $65(14)$ & $28(17)$ & Jamali et al. (2007) \\
\hline $17(39)$ & $9(23)$ & $50(16)$ & $1532(0)$ & $58(205)$ & $104(12)$ & $59(13)$ & Gerstenfeld et al. (2003) \\
\hline $19(38)$ & $12(22)$ & $50(16)$ & $1532(0)$ & $193(127)$ & $43(16)$ & $32(16)$ & Caplan and Correa (2011) \\
\hline $20(37)$ & $3(27)$ & $154(10)$ & $1532(0)$ & $117(160)$ & $131(11)$ & $32(16)$ & Schnabel et al. (2009) \\
\hline
\end{tabular}

$\mathrm{TC}_{\text {year }-1}$ : number of citations from JCR year to articles in "year - 1"

$\mathrm{TC}_{\text {year-2 } 2}$ : number of citations from JCR year to articles in "year - 2"

$\mathrm{C}_{0}$ : total number of citations from web of science core collection in publication year

$\mathrm{TC}_{2018}$ : total number of citations from web of science core collection since publication to the end of 2018

$\mathrm{C}_{2018}$ : total number of citations from web of science core collection in 2018

TCPY: total number of citations per number of year $\left(\mathrm{TC}_{2018} /\right.$ year $)$

J Orthop Res was classified in the Web of Science category of orthopedics. Figure 1 shows its journal impact factor and ranking within the subject category from 1997 to 2018. Journal impact factor (JIF) slightly increased with fluctuate trend was found. Ranking of J Orthop Res in the Web of Science category of orthopedics was decreased. How quickly recent publications are cited is an important factor that can affect IF [13]. In general, citations per publication for articles in a journal would have a sharp increase 
after publication and would reach a peak in a specific year. Figure 2 shows citations per publication for each year of article [28]. The peak year of citations per publication was found to be in the $5^{\text {th }}$ full year since its publication year. The peak year could be different, for example, the $7^{\text {th }}$ year for Revista de Biología Tropical [12]. A special case was reported that it does not show a peak, unlike previous findings, but shows an increasing trend without a peak after $4^{\text {th }}$ and $9^{\text {th }}$ year for Journal of Membrane Science [1] and Polish Journal of Environmental Studies [25] respectively. Since IF only considers citations within two years after publication, the $I F$ of J Orthop Res would be higher if it was calculated after a couple of years. It was pointed that $I F$ is not an unbiased criterion for all journals, since peak year citations per publication of each journal can be different from each other [25].

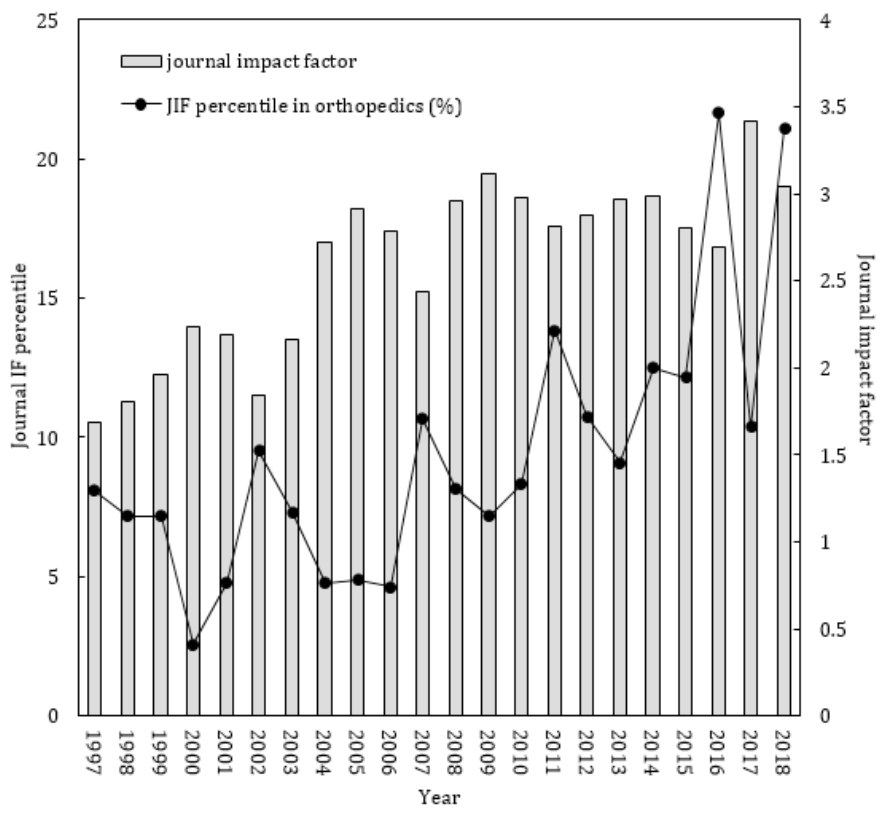

Figure 1: Rankings of Journal of Orthopaedic Research by journal impact factor (JIF) in Web of Science category of orthopedics from 1997 to 2018.

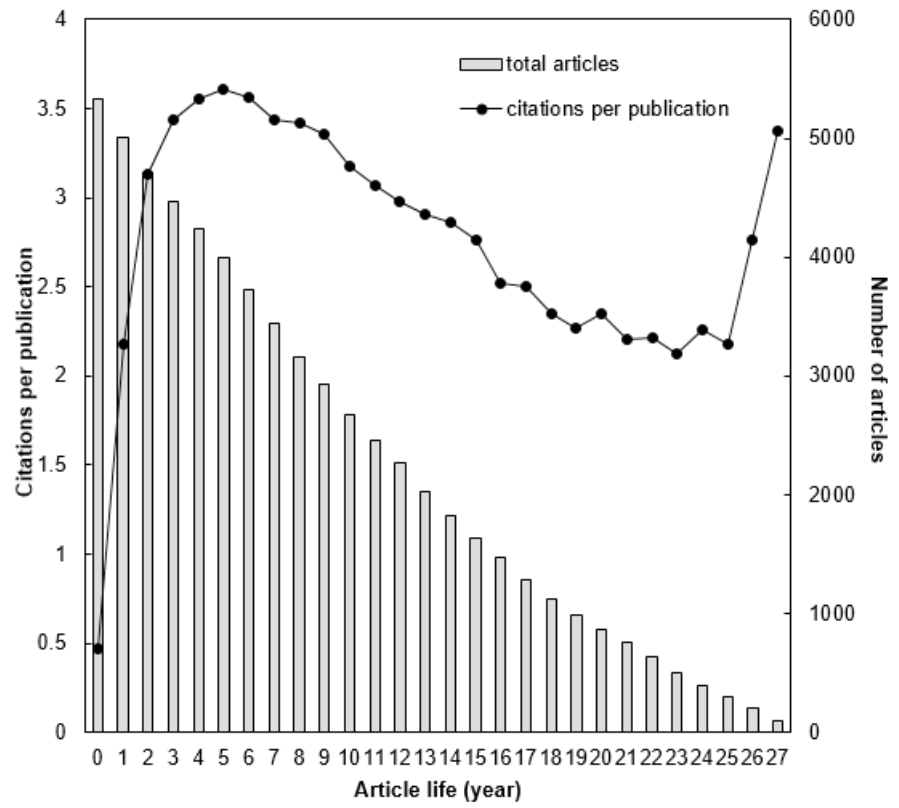

Figure 2: Trend of citations per publication.

Trends of number of articles and citations per publication

Trends of number of articles shows a journal's development and citations per publication gives information about impact of a journal in research world. Trends of the number of annual articles $(T P)$ and their citations per publication $\left(C P P_{2018}=T C_{2018} / T P\right)$ has been proposed to discover the development of a journal $[1,12]$. Of the 5,329 articles published in J Orthop Res, the annual number of 
articles increased about 3.2-fold from 101 in 1991 to 328 in 2018 (Figure 3). The number of annual articles were increased fluctuate. Minima number of articles was found in 1994 with 94 articles. In 1991, 101 articles had the highest $C P P_{2018}$ of 91, which can be attributed to the top ten most frequently cited articles by Caplan [29] with $T C_{2018}$ of 2,243 (ranked $1^{\text {st }}$ ), [30] with $T C_{2018}$ of 607 (ranked $2^{\text {nd }}$ ); and [31] with $T C_{2018}$ of 497 (ranked $7^{\text {th }}$ ).

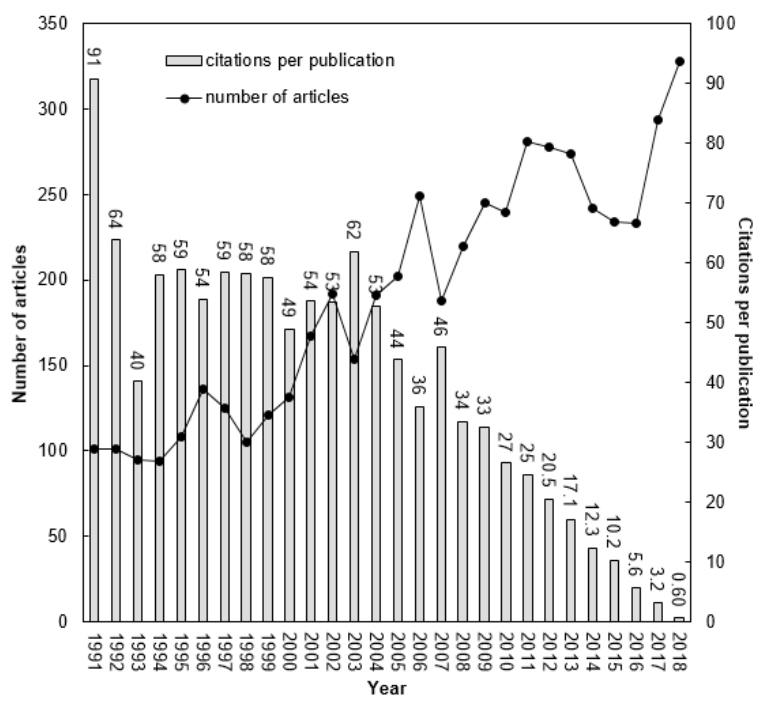

Figure 3: Number of articles and citations per publication versus year for J Orthop Res.

\section{Characteristics of countries, institutions, and authors}

Excluding 16 articles without any author affiliation information on SCI-EXPANDED, the remaining 5,313 articles originated from 57 countries. Among those articles, 4,295 (81\% of 5,313 articles) were single country articles, while 1,018 (19\%) were internationally collaborative articles. Table 3 shows the top 10 most contributing countries with six publication indicators such as number total of articles $(T P)$, country independent articles (IP), internationally collaborative articles $(C P)$, first author articles $(F P)$, corresponding author articles $(R P)$, single author articles $(S P)$, and citations per publication $\left(C P P_{2018}=T C_{2018} / T P\right)[1,25]$. The advantage of using $C P P_{2018}$ and $T C_{2018}$ is that it is invariant in comparison with the index of citations from the Web of Science Core Collection which has to be updated from time to time [24]. Four European countries, three Asian countries, two American countries, and one Oceania country were ranked on the top 10 of total articles. The most productive African country was Egypt with five articles ranked $37^{\text {th }}$. USA dominated in J Orthop Res, ranking the first in all six publication indicators with $T P$ of 2,974 articles ( $56 \%$ of 5,313 articles), IP of 2,309 articles (54\% of 4,295 country independent articles), CP of 665 articles ( $65 \%$ of 1,018 internationally collaborative articles), FP of 2,720 articles (51\% of 5,313 first author articles), RP of 2,520 articles ( $50 \%$ of 5,024 corresponding author articles), and $S P$ of 19 articles (73\% of 26 single author articles). USA also had the highest $C P P_{2018}$ of 39 . China ranked $6^{\text {th }}$ in total articles but have lower $C P P_{2018}$ of 19.

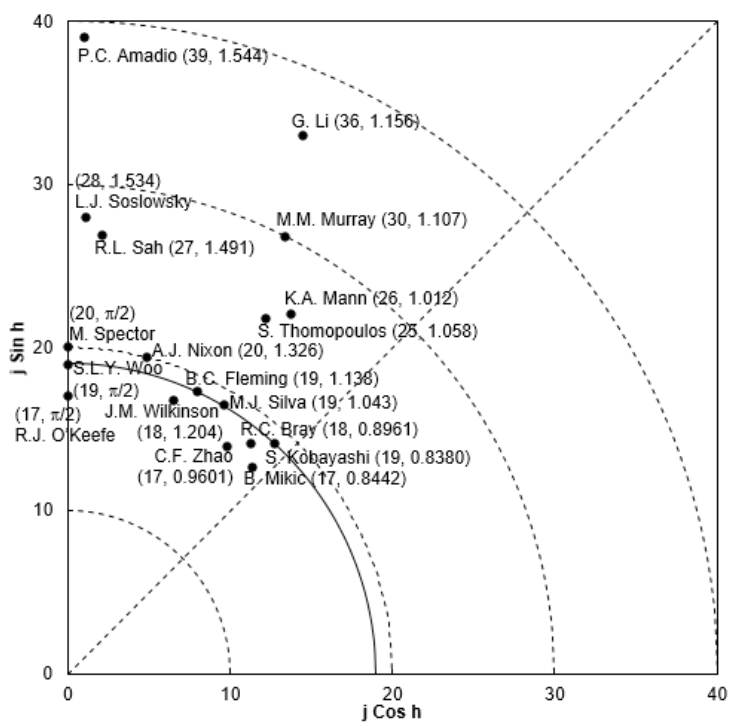

Figure 4: Top 18 authors with $Y$-index $(j \geq 17)$. 
Table 3: Characteristics of the top 10 productive countries.

\begin{tabular}{|c|c|c|c|c|c|c|c|c|}
\hline Country & TP & TP & IP & CP & FP & RP & SP & R (\%) \\
\hline USA & 2,974 & $1(56)$ & $1(54)$ & $1(65)$ & $1(51)$ & $1(50)$ & $1(73)$ & 39 \\
\hline Japan & 525 & $2(9.9)$ & $2(8.5)$ & $3(16)$ & $2(7.9)$ & $2(8.1)$ & N/A & 24 \\
\hline Germany & 369 & $3(6.9)$ & $4(5.0)$ & $4(15)$ & $4(5.4)$ & $3(5.7)$ & N/A & 30 \\
\hline Canada & 353 & $4(6.6)$ & $3(5.3)$ & $6(12)$ & $3(5.5)$ & $4(5.4)$ & $2(7.7)$ & 28 \\
\hline UK & 299 & $5(5.6)$ & $5(4.0)$ & $5(12)$ & $5(4.3)$ & $5(4.5)$ & $2(7.7)$ & 33 \\
\hline China & 257 & $6(4.8)$ & $6(3.6)$ & $7(10)$ & $6(3.8)$ & $6(3.8)$ & N/A & 19 \\
\hline Switzerland & 221 & $7(4.2)$ & $11(1.4)$ & $2(16)$ & $10(2.0)$ & $10(2.0)$ & N/A & 34 \\
\hline Australia & 189 & $8(3.6)$ & $8(2.5)$ & $8(8.0)$ & $7(2.8)$ & $7(2.8)$ & N/A & 31 \\
\hline Netherlands & 171 & $9(3.2)$ & $9(2.3)$ & $9(7.3)$ & $8(2.4)$ & $8(2.4)$ & N/A & 33 \\
\hline Taiwan & 146 & $10(2.7)$ & $7(2.7)$ & $16(3.1)$ & $9(2.3)$ & $9(2.4)$ & $5(3.8)$ & 32 \\
\hline
\end{tabular}

TP: Total number of articles; IP: Country independent articles; CP: Internationally collaborative articles; FP: First author articles; RP: Corresponding author articles; SP: Single author articles; $\mathrm{CPP}_{2018}$ : Citations per publication (CP$\left.\mathrm{P}_{2018}=\mathrm{TC}_{2018} / \mathrm{TP}\right) ; \mathrm{N} / \mathrm{A}$ : Not available.

Table 4: Characteristics of the top ten productive institutes.

\begin{tabular}{|c|c|c|c|c|c|c|c|c|c|}
\hline Institute & TP & $\begin{array}{c}\text { TP R } \\
(\%)\end{array}$ & IP R (\%) & $\begin{array}{c}\text { ICP R } \\
(\%)\end{array}$ & $\begin{array}{c}\text { NCP R } \\
(\%)\end{array}$ & $\begin{array}{c}\text { FP R } \\
(\%)\end{array}$ & $\begin{array}{c}\mathbf{R P ~ R} \\
(\%)\end{array}$ & $\begin{array}{c}\text { SP R } \\
(\%)\end{array}$ & CPP \\
\hline Ha18
\end{tabular}

TP: Total number of articles; IP: Institute independent articles; ICP: Internationally collaborative articles; NCP: Nationally collaborative articles; FP: First author articles; RP: Corresponding author articles; SP: Single author articles; $\mathrm{CPP}_{2018}$ : Citations per publication $\left(\mathrm{CPP}_{2018}=\mathrm{TC}_{2018} / T P\right) ; \mathrm{N} / \mathrm{A}$ : Not available.

Of the total 5,313 articles with affiliation information in SCIEXPANDED, 1,983 articles (37\% of 5,313 articles) came from independent institutions with $C P P_{2018}$ of $35 ; 3,330$ articles $(63 \%)$ from inter-institutional collaborations with $C P P_{2018}$ of 32; included 1,018 articles $(31 \%$ of 3,330 inter-institutionally collaborative articles) from international collaborations with $C P P_{2018}$ of 31 and 2,312 articles (69\%) from national collaborations with $C P P_{2018}$ of 33 . Percentage of the inter-institutional collaboration rate of J Orthop Res (63\%) was found much higher than that of J Membr Sci (38\%) [1] and Pol J Environ Stud (31\%) [25]. Table 4 demonstrates the characteristics of the top 10 productive institutions. Nine of them were located in USA and one in Canada. Harvard University took the leading position in three of the seven publication indicators with TP of 163 articles (3.1\% of 5,313 articles), ICP of 53 articles (5.2\% of 1,018 internationally collaborative articles), and NCP of 91 articles (3.9\% of 2,312 nationally collaborative articles). University of Calgary in Canada ranked top with IP of 54 articles $(2.7 \%$ of 1,983 institutional independent articles) while University of Pittsburgh ranked top with $F P$ of 89 articles (1.7\% of 5,313 first-author articles) and $R P$ of 76 articles ( $1.5 \%$ of 5,024 corresponding-author articles). In addition, University of California Davis published 64 articles (ranked $18^{\text {th }}$ ) including the most single-author articles with SP of four articles (15\% of 26 single-author articles). Harvard University, University of Pittsburgh, and Cornell University had the highest $C P P_{2018}$ of 48 respectively. In the top ten productive institutes, Harvard University was the only one who published single author 
articles in J Orthop Res. It has been generally accepted that the first author and the corresponding author are the most significant author position [32,33]. Three bibliometric indicators such as total articles $(T P)$, first author articles $(F P)$, and corresponding author articles $(R P)$ were applied for an analysis of authors' publications in a journal $[18,34]$. Table 5 lists the top ten authors with at least 33 articles in J Orthop Res Of the 5,329 articles with author's information were published by 17,001 authors. There were 5,329 articles by 4,150 first authors, 4,889 articles with corresponding information by 2,732 corresponding authors, and 26 single author articles by 21 authors. K.N. An contributed the most with 68 articles. P.C. Amadio published the most corresponding author articles with 38 while K.A. Mann and G. Li published the most first author articles with 11 respectively. B. Martin published the most first single author articles with three. S.L.Y. Woo with 44 articles had the highest $C P P_{2018}$ of 76 followed by G. Li with $C P P_{2018}$ of 57 and L.J. Soslowsky with $C P P_{2018}$ of 51. M.M. Murray had highest $T C_{\text {year-1 }}+$ $T C_{\text {year-2 }}$ of 314. Only two productive authors M.M. Murray and S.L.Y. Woo were journal impact factor contributors (JIF contributors) who published high journal impact factor contributing articles with $T C_{\text {year-1 }}+T C_{\text {year-2 }}$ of 48 for articles by Murray et al. [35] and Gabriel et al. [36] respectively. Bias is always considered in authorship analysis because two or more authors may have the same name, or authors used different names in their publications (e.g. name changes due to marriage) [19].

Table 5: Characteristics of the top ten productive authors.

\begin{tabular}{|c|c|c|c|c|c|c|c|}
\hline Author & TP & Rank (TP) & Rank (FP) & Rank (RP) & $\mathrm{TC}_{2018}$ & $\mathrm{CPP}_{2018}$ & $\mathrm{TC}_{\text {year-1 }}+\mathrm{TC}_{\text {year-2}}$ \\
\hline KN An & 68 & $1(68)$ & $781(1)$ & $84(6)$ & 1,777 & 26 & 234 \\
\hline PC Amadio & 53 & $2(53)$ & $781(1)$ & $1(38)$ & 1,000 & 19 & 207 \\
\hline CF Zhao & 46 & $3(46)$ & $12(7)$ & $28(10)$ & 750 & 16 & 169 \\
\hline SLY Woo & 44 & $4(44)$ & $\mathrm{N} / \mathrm{A}$ & 7 (19) & 3,347 & 76 & 232 \\
\hline LJ Soslowsky & 40 & $5(40)$ & $781(1)$ & $2(27)$ & 2,026 & 51 & 309 \\
\hline CB Frank & 39 & $6(39)$ & $781(1)$ & $13(15)$ & 1,192 & 31 & 180 \\
\hline MM Murray & 36 & $7(36)$ & $3(10)$ & $5(20)$ & 1,400 & 39 & 314 \\
\hline NG Shrive & 34 & $8(34)$ & $\mathrm{N} / \mathrm{A}$ & $403(2)$ & 937 & 28 & 153 \\
\hline EM Schwarz & 34 & $8(34)$ & $74(3)$ & $14(13)$ & 1,266 & 37 & 225 \\
\hline G Li & 33 & $10(33)$ & $1(11)$ & $3(25)$ & 1,876 & 47 & 261 \\
\hline
\end{tabular}

TP: Total number of articles; FP: First author articles; RP: Corresponding author articles; TC 2018 : The total number of citations from web of science core collection since publication to the end of 2018; $\mathrm{CPP}_{2018}$ : Citations per publication

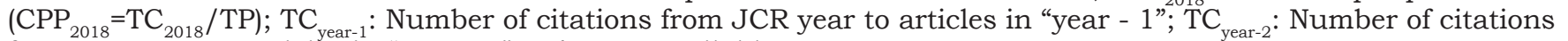
from JCR year to articles in "year - 2"; N/A: not available.

Ho $[18,22,37]$ proposed the $Y$-index which is related to the numbers of first author publications $(F P)$ and corresponding author publications $(R P)$. The $Y$-index with two parameters $(j, h)$, assess both the publication potential and characteristics of contribution as a single index. The $Y$-index is defined as [22,37]:

$$
\begin{aligned}
& j=F P+R P \\
& h=\tan ^{-1}\left(\frac{R P}{F P}\right)
\end{aligned}
$$

$j$ indicates publication potential. It was calculated by using numbers of first authored articles and corresponding authored articles as the Eq. (1). When one had larger $j$, it means its $Y$-index located far away from origin of the polar coordinates. It indicates that one published more articles as "important author" [37]. $h$ is a publication characteristic constant, that introduces the distribution of the numbers of the corresponding authored articles and the first authored articles. $h$ could be calculated by using Eq. (2). When the number of the first authored articles and the number of the corresponding authored articles are the same, $Y$-index is located in the 45 -degree $(0.7854 \mathrm{rad})$ line with the same $h$ of 0.7854 . When $j>0.7854$, it means one published more corresponding author articles, and when $j<0.7854$, it means one published more first author articles. When $h=0, j=$ number of first author articles, and $h=\pi / 2, j=$ number of corresponding author articles.

Of the 5,329 articles published in J Orthop Res, 4,889 articles ( $92 \%$ of 5,329 articles) with both first author and corresponding author's names in the SCI-EXPANDED were extensively analyzed by using the $Y$-index. A total of 4,889 articles were contributed by 15,911 authors. Only 1,803 authors (11\% of the 15,911 authors) had both first- and corresponding-author articles in J Orthop Res In particular, 929 authors (5.8\% of the 15,911 authors) had only corresponding-author articles $(h=\pi / 2) ; 334$ (2.1\%) authors had more corresponding-author articles than first-author articles $(\pi / 2>h>0.7854) ; 1,343$ (8.4\%) authors had the equivalent numbers of first-author and corresponding-author articles ( $h=0.7854) ; 126$ $(0.79 \%)$ authors had more first-author articles than correspondingauthor articles $(0.7854>h>0)$; and $11,162(70 \%)$ authors had neither first- nor corresponding-author articles with $Y$-index of $(0$, $0)$. Figure 4 shows distribution of the $Y$-index $(j, h)$ of the top 18 contributing authors with $j \geq 17$ ( $j \operatorname{Cos} h$ and $j \operatorname{Sin} h$ are chosen as the $x$ and $y$ coordinate axes). Each point has a coordinate $(j, h)$ that could symbolize a single-author or multiple authors. $j$ is contributed constant, an author with a higher $j$ indicates more articles as first 
or corresponding authors. P.C. Amadio $(39,1.544)$, G. Li $(36,1.156)$, and M.M. Murray $(30,1.107)$ were the top three contributors on J Orthop Res Contributing characteristics constant, $h$, could help to obtain the different proportion of corresponding author articles to first author articles. $Y$-index is helpful to distinguish the different performance of authors especially when $j$ of authors is the same. For example, the $j$ of S.L.Y. Woo $(19, \pi / 2)$, B.C. Fleming $(19,1.138)$, M.J. Silva $(19,1.043)$, and S. Kobayashi $(19,0.838)$ were all the same of 19. However, $h$ of Woo was $\pi / 2$, Fleming was 1.138; Silva was 1.043, and Kobayashi was 0.838. That means Woo had greater proportion of corresponding author articles to first author articles than Fleming, Silva, and Kobayashi. All top 18 authors published more corresponding author articles than first author articles in J Orthop Res $(h>0.7854)$. Within these top 18 authors, M. Spector $(20, \pi / 2)$, S.L.Y. Woo $(19, \pi / 2)$, and R.J. O'Keefe $(17, \pi / 2)$ had only corresponding author articles $(h=\pi / 2)$. Furthermore, K.N. An published the most 68 articles in J Orthop Res, including one first author and six corresponding articles with $Y$-index $(7,1.406)$. A bias would appear in authorship analysis because two or more authors may have the same name, or authors used different names in their publications [19].

\section{Highly cited articles}

The total citation count was obtained from web of science core collection, and this shows the total number of times that an article was cited by the journals listed in the Web of Science Core Collection database. The hotspots in a research field might be reflected by highly cited articles [38]. Highly cited publications in a journal were also investigated, for example JAMA-Journal of the American Medical Association [14], Water Research [19] and Polish Journal of Environmental Studies [25]. Articles with $T C_{2018} \geq 100$, were generally called highly cited articles [37,39]. In J Orthop Res, 333 of 5,329 articles were highly cited articles with $T C_{2018} \geq 100$. The top 10 highly cited articles were listed in Table 6. All the top 10 highly cited articles were published in the 1990s. The earliest highly cited was published in 1991 by Caplan [29], Schipplein [30] \& Athanasiou et al. [31]. The latest highly cited articles were published in 1999 by Mckellop et al. [40] \& Vunjak-Novakovic et al. [41]. Three highly cited articles with $T C_{2018} \geq 100$ such as articles by Caplan [29], Markolf et al. [42] \& Schipplein [30] in J Orthop Res were also ranked top ten in $C_{2018}$. The 10 highly cited articles were published by 45 highly cited authors from 18 institutions. Three of the top ten articles were published by authors from case Western Reserve University in USA. These top ten articles were published by USA while one was international collaboration with Switzerland. Caplan AI $[29,43]$ and AJ Grodzinsky $[41,44]$ published two the top cited articles respectively (Table 6). Citation histories of the top ten most frequently cited articles in J Orthop Res Were shown in Figure 5. The highly cited article about mesenchymal stem cells by Caplan [29] had different citation development trend. There is a sharply increased trend after publication year of 1991 for two decades to reach a plateau in recent years. Highly cited articles would not be always with high citations. Article by Buschmann et al. [44] with $T C_{2018}$ of 395 had low citation in the most recent year of 2018 with $C_{2018}$ of 7 .

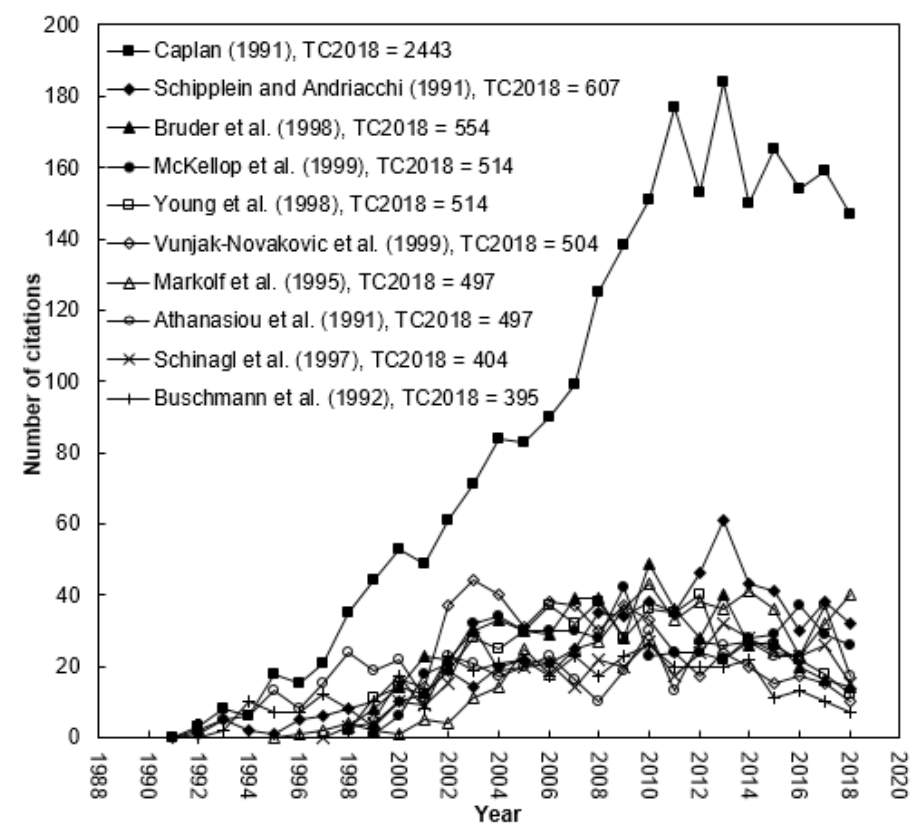

Figure 5: Citation histories of the top ten most frequently cited articles.

\section{Distribution of words in article title and author keywords}

The title of article directly provided a picture of an article's theme. The synthesized analysis of words in article titles was developed and applied in last decade [38]. Prepositions, articles, and conjunctions were discarded in this analysis [45]. Bone (16\% of 5,329 articles), model (11\%), human (10\%) cartilage $(8.6 \%)$, cells $(8.4 \%)$, knee $(8.1 \%)$, effect $(6.7 \%)$, healing $(6.7 \%)$, tendon $(6.5 \%)$, and expression $(6.5 \%)$ were the top ten most frequently 
used single words in article titles in the period of 1991-2018 in J Orthop Res Knee (8.1\%), osteoarthritis (4.5\%), mesenchymal (1.5\%), signaling (1.3\%), head $(1.2 \%)$, and plasma $(0.77 \%)$ in in (2.6\%), differentiation (2.1\%), ACL (1.6\%), rotator $(1.5 \%)$, cuff

Table 6: Top 10 highly cited articles in Journal of Orthopaedic Research.

\begin{tabular}{|c|c|c|c|}
\hline $\begin{array}{c}\text { Rank } \\
\left(\mathrm{TC}_{2018}\right)\end{array}$ & $\begin{array}{l}\text { Rank } \\
\left(\mathrm{C}_{2018}\right)\end{array}$ & Article Titles & References \\
\hline $1(2,443)$ & $1(147)$ & Mesenchymal stem cells & Caplan (1991) \\
\hline $2(607)$ & $7(32)$ & $\begin{array}{c}\text { Interaction between active and passive knee stabilizers during level } \\
\text { walking }\end{array}$ & Schipplein [30] \\
\hline $3(554)$ & $65(14)$ & $\begin{array}{l}\text { Bone regeneration by implantation of purified, culture-expanded human } \\
\text { mesenchymal stem cells }\end{array}$ & Bruder et al. [48] \\
\hline $4(514)$ & $11(26)$ & $\begin{array}{l}\text { Development of an extremely wear-resistant ultra high molecular weight } \\
\text { polyethylene for total hip replacements }\end{array}$ & Mckellop et al. [40] \\
\hline $4(514)$ & $104(12)$ & $\begin{array}{l}\text { Use of mesenchymal stem cells in a collagen matrix for Achilles tendon } \\
\text { repair }\end{array}$ & Young et al. [43] \\
\hline $6(504)$ & $169(10)$ & $\begin{array}{l}\text { Bioreactor cultivation conditions modulate the composition and mechan- } \\
\text { ical properties of tissue-engineered cartilage }\end{array}$ & Vunjak-Novakovic et al. [41] \\
\hline $7(497)$ & $2(40)$ & $\begin{array}{c}\text { Combined knee loading states that generate high anterior cruciate } \\
\text { ligament forces }\end{array}$ & Markolf et al. [42] \\
\hline $7(497)$ & $38(17)$ & $\begin{array}{l}\text { Interspecies comparisons of insitu intrinsic mechanical-properties of } \\
\text { distal femoral cartilage }\end{array}$ & Athanasiou et al. [31] \\
\hline $9(404)$ & $55(15)$ & $\begin{array}{l}\text { Depth-dependent confined compression modulus of full-thickness } \\
\text { bovine articular cartilage }\end{array}$ & Schinagl et al. [51] \\
\hline $10(395)$ & $375(7)$ & $\begin{array}{c}\text { Chondrocytes in agarose culture synthesize a mechanically functional } \\
\text { extracellular-matrix }\end{array}$ & Buschmann et al. [44] \\
\hline
\end{tabular}

$\mathrm{TC}_{2018}$ : total number of citations from web of science core collection since publication to the end of 2018.

$\mathrm{C}_{2018}$ : total number of citations from web of science core collection in 2018.

Distribution of author keywords by years can be information for research trends [46]. There were 7,789 author keywords in 4,037 articles in J Orthop Res from 1991 to 2018. The most frequently used keyword was "osteoarthritis" which was used in 309 articles (7.7\% of 4,037 articles), followed by biomechanics (196 articles [47-51]; 4.9\%), cartilage (194 articles; 4.8\%), knee (132 articles; $3.3 \%$ ), fracture healing (126 articles; $3.1 \%$ ), collagen (108 articles; $2.7 \%$ ), tendon (107 articles; $2.7 \%$ ), animal model (97 articles; $2.4 \%$ ), bone (90 articles; $2.2 \%$ ), and anterior cruciate ligament (89 articles; $2.2 \%$ ) were associated with hot topics in J Orthop Res. In addition, keywords included osteoarthritis, cartilage, biomechanics, knee, intervertebral disc, fracture healing, animal model, tendon, inflammation, and collagen, ranked top ten in the most recent period of 2012 and 2018.

\section{Conclusion}

In total of 5,589 publications in 11 Web of Science document types were published in J Orthop Res from 1991 to 2018. Article was the dominant document type and had a $C P P_{2018}$ of 33 but review had only half of $C P P_{2018}$ with 16 . The peak year of citations per publication was found to be in the $5^{\text {th }}$ full year since its publication year. USA published the most articles and had higher citations per publication. Harvard University contributed the most articles in J Orthop Res. Results of citation analysis may have provided some initial evidences that highly cited articles in a journal might not contribute a lot to the journal's impact factor. Articles related to osteoarthritis, biomechanics, cartilage, knee, and fracture healing were the most popular topics while intervertebral disc, tissue engineering, and apoptosis were new focuses in the journal.

\section{References}

1. Fu HZ, Ho YS (2015) A bibliometric analysis of the Journal of membrane science (1976-2010). Electronic Library 33(4): 698-713.

2. Coronado RA, Riddle DL, Wurtzel WA, George SZ (2011) Bibliometric analysis of articles published from 1980 to 2009 in Physical Therapy, journal of the american physical therapy association. Physical Therapy 91(5): 642-655.

3. Wiles L, Matricciani L, Williams M, Olds T (2012) Sixty-five years of Physical Therapy: Bibliometric analysis of research publications from 1945 through 2010. Physical Therapy 92(4): 493-506.

4. Coronado RA, Wurtzel WA, Simon CB, Riddle DL, George SZ (2011) Content and bibliometric analysis of articles published in the journal of orthopaedic \& sports physical therapy. Journal of Orthopaedic \& Sports Physical Therapy 41(12): 920-931.

5. Yalcinkaya M, Bagatur AE (2014) Articles published in acta orthopaedica et traumatologica turcica between 2003-2012: Content, characteristics and publication trends. Acta Orthopaedica et Traumatologica Turcica 48(5): 576-583.

6. Mavrogenis AF, Megaloikonomos PD, Panagopoulos GN, Mauffrey C, Quaile A, et al. (2017) Best one hundred papers of International Orthopaedics: A bibliometric analysis. International Orthopaedics 41(4): 689-697. 
7. Sheridan G, Wisken E, Hing CB, Smith TO (2018) A bibliometric analysis assessing temporal changes in publication and authorship characteristics in The Knee from 1996 to 2016. Knee 25(2): 213-218.

8. Russell AF, Nguyen M, Bhuiya M, Likine EF, Fischer JP, et al. (2018) Comparative analysis of bibliometric, authorship, and collaboration trends over the past 30-year publication history of the journal of orthopaedic trauma and injury. Journal of Orthopaedic Trauma 32(8): E327-E333.

9. Brinker AR, Liao JL, Kraus KR, Young J, Sandelski M, et al. (2018) Bibliometric analysis of gender authorship trends and collaboration dynamics over 30 years of Spine 1985 to 2015. Spine 43(14): E849-E854.

10. Seetharam A, Ali MT, Wang CY, Schultz KE, Fischer JP, et al. (2018) Authorship trends in the journal of orthopaedic research: A bibliometric analysis. Journal of Orthopaedic Research 36(11): 3071-3080.

11. Li YZ, Xu G, Long X, Ho YS (2019) A bibliometric analysis of classic publications in web of science category of orthopedics. Journal of Orthopaedic Surgery and Research 14(1): 227.

12. Monge-Nájera J, Ho YS (2016) Bibliometry of the revista de biología tropical/international journal of tropical biology and conservation: Document types, languages, countries, institutions, citations and article lifespan. Revista de Biología Tropical 64(3): 1223-1235.

13. Garfield E (1999) Journal impact factor: A brief review. Canadian Medical Association Journal 161(8): 979-980.

14. Garfield E (1997) Dispelling a few common myths about journal citation impacts. Scientist 11(3): 11.

15. Ho YS, Kahn M (2014) A bibliometric study of highly cited reviews in the Science Citation Index Expanded ${ }^{\mathrm{TM}}$. Journal of the Association for Information Science and Technology 65(2): 372-385.

16. Wang MH, Fu HZ, Ho YS (2011) Comparison of universities' scientific performance using bibliometric indicators. Malaysian Journal of Library \& Information Science 16(2): 1-19.

17. Chuang KY, Wang MH, Ho YS (2011) High-impact papers presented in the subject category of water resources in the Essential Science Indicators database of the Institute for Scientific Information. Scientometrics 87(3): 551-562.

18. Ho YS (2012) Top-cited articles in chemical engineering in science citation index expanded: A bibliometric analysis. Chinese Journal of Chemical Engineering 20(3): 478-488.

19. Wang MH, Yu TC, Ho YS (2010) A bibliometric analysis of the performance of water research. Scientometrics 84(3): 813-820.

20. Li Z, Ho YS (2008) Use of citation per publication as an indicator to evaluate contingent valuation research. Scientometrics 75(1): 97-110.

21. Ho YS, Fu HZ (2016) Mapping of metal-organic frameworks publications: A bibliometric analysis. Inorganic Chemistry Communications 73: 174182.

22. Ho YS (2014a) Classic articles on social work field in Social Science Citation Index: A bibliometric analysis. Scientometrics 98(1): 137-155.

23. Chiu WT, Ho YS (2005) Bibliometric analysis of homeopathy research during the period of 1991 to 2003. Scientometrics 63(1): 3-23.

24. Fu HZ, Wang MH, Ho YS (2012) The most frequently cited adsorption research articles in the Science Citation Index (Expanded). Journal of Colloid and Interface Science 379(1): 148-156.

25. Chuang KY, Olaiya MU, Ho YS (2012) Bibliometric analysis of the Polish Journal of Environmental Studies (2000-11). Polish Journal of Environmental Studies 21(5): 1175-1183.

26. Anderson DD, Chubinskaya S, Guilak F, Martin JA, Oegema TR, et al (2011) Post-traumatic osteoarthritis: Improved understanding and opportunities for early intervention. Journal of Orthopaedic Research 29(6): 802-809.
27. Gabriel MT, Wong EK, Woo SLY, Yagi M (2004) Distribution of in situ forces in the anterior cruciate ligament in response to rotatory loads. Journal of Orthopaedic Research 22(1): 85-89.

28. Chuang KY, Huang YL, Ho YS (2007) A bibliometric and citation analysis of stroke-related research in Taiwan. Scientometrics 72(2): 201-212.

29. Caplan AI (1991) Mesenchymal stem cells. Journal of Orthopaedic Research 9(5): 641-650.

30. Schipplein OD, Andriacchi TP (1991) Interaction between active and passive knee stabilizers during level walking. Journal of Orthopaedic Research 9(1): 113-119.

31. Athanasiou KA, Rosenwasser MP, Buckwalter JA, Malinin TI, Mow VC (1991) Interspecies comparisons of insitu intrinsic mechanical properties of distal femoral cartilage. Journal of Orthopaedic Research 9(3): 330-340.

32. Gaeta TJ (1999) Authorship: "law" and order. Academic Emergency Medicine 6(4): 297-301.

33. Mattsson P, Sundberg CJ, Laget P (2011) Is correspondence reflected in the author position? A bibliometric study of the relation between corresponding author and byline position. Scientometrics 87(1): 99105.

34. Ho HC, Ho YS (2015) Publications in dance field in Arts \& Humanities Citation Index: A bibliometric analysis. Scientometrics 105(2): 10311040.

35. Murray MM, Spindler KP, Abreu E, Muller JA, Nedder A, et al. (2007) Collagen-platelet rich plasma hydrogel enhances primary repair of the porcine anterior cruciate ligament. Journal of Orthopaedic Research 25(1): 81-91.

36. Gabriel MT, Wong EK, Woo SLY, Yagi M, Debski RE (2004) Distribution of in situ forces in the anterior cruciate ligament in response to rotatory loads. Journal of Orthopaedic Research 22(1): 85-89.

37. Ho YS (2014b) A bibliometric analysis of highly cited articles in materials science. Current Science 107(9): 1565-1572.

38. Ho YS, Satoh H, Lin SY (2010) Japanese lung cancer research trends and performance in Science Citation Index. Internal Medicine 49(20): 22192228.

39. Hsu YHE, Ho YS (2014) Highly cited articles in health care sciences and services field in science citation index expanded: A bibliometric analysis for 1958-2012. Methods of Information in Medicine 53(6): 446-458.

40. McKellop H, Shen FW, Lu B, Campbell P, Salovey R (1999) Development of an extremely wear-resistant ultra-high molecular weight polyethylene for total hip replacements. Journal of Orthopaedic Research 17(2): 157167.

41. Vunjak-Novakovic G, Martin I, Obradovic B, Treppo S, Grodzinsky AJ, et al. (1999) Bioreactor cultivation conditions modulate the composition and mechanical properties of tissue-engineered cartilage. Journal of Orthopaedic Research 17(1): 130-138.

42. Markolf KL, Burchfield DI, Shapiro MM, Shepard ME, Finerman GAM, et al. (1995) Combined knee loading states that generate high anterior cruciate ligament forces. Journal of Orthopaedic Research 13(6): 930935.

43. Young RG, Butler DL, Weber W, Caplan AI, Gordon SL, et al. (1998) Use of mesenchymal stem cells in a collagen matrix for Achilles tendon repair. Journal of Orthopaedic Research 16(4): 406-413.

44. Buschmann MD, Gluzband YA, Grodzinsky AJ, Kimura JH, Hunziker EB (1992) Chondrocytes in agarose culture synthesize a mechanically functional extracellular matrix. Journal of Orthopaedic Research 10(6): 745-758.

45. Xie SD, Zhang J, Ho YS (2008) Assessment of world aerosol research trends by bibliometric analysis. Scientometrics 77(1): 113-130. 
46. Zhang GF, Xie SD, Ho YS (2010) A bibliometric analysis of world volatile organic compounds research trends. Scientometrics 83(2): 477-492.

47. Brimblecombe P, Grossi CM (2009) The bibliometrics of atmospheric environment. Atmospheric Environment 43(1): 9-12.

48. Bruder SP, Kurth AA, Shea M, Hayes WC, Jaiswal N, et al. (1998) Bone regeneration by implantation of purified, culture-expanded human mesenchymal stem cells. Journal of Orthopaedic Research 16(2): 155162.
49. Bujdoso E, Lyon WS, Braun T (1981) Scientometric study of health physics. Health Physics 41(2): 233-242.

50. Monge-Nájera J, Ho YS (2012) Costa rica publications in the science citation index expanded: A bibliometric analysis for 1981-2010. Revista de Biología Tropical 60(4): 1649-1661.

51. Schinagl RM, Gurskis D, Chen AC, Sah RL (1997) Depth-dependent confined compression modulus of full-thickness bovine articular cartilage. Journal of Orthopaedic Research 15(4): 499-506.

For possible submissions Click below: 